\title{
Low-Income Families: Experiences and Responses to Consumer Exclusion
}

\begin{abstract}
Purpose: This paper focuses on low-income families who are excluded from consumer culture. It explores their experiences and responses to material deprivation, social deprivation and stigmatization.
\end{abstract}

Methodology: Given the need for identification and calculation of exclusion thresholds to be supplemented by the voice of the excluded themselves, the study is based on qualitative analysis of 30 in-depth interviews with low-income families who encounter consumption constraints in the marketplace.

Findings: While the harsh realities of consumer exclusion cannot be denied, findings also present a more positive outlook as excluded consumers can achieve empowerment through employment of stigma management strategies, creative consumer coping and rejection of the stigmatising regime.

Research limitations: Research is based only on families with children under the age of 18; future research on older people and exclusion would prove a useful comparison.

Practical Implications: The research raises a number of important policy issues in relation to social barriers to inclusion and the role of marketing in contributing to consumer exclusion.

Originality/Value: Social policy studies surrounding social exclusion in terms of separation from mainstream society tend to focus on employment. This paper highlights that a social exclusion discourse can also provide a useful perspective to investigate exclusion in relation to consumerism.

Classification: Research paper

Keywords: social exclusion, stigmatization, low-income, consumerism 


\section{Low-Income Families: Experiences and Responses to Consumer Exclusion}

\section{Introduction}

It has been suggested that "An individual is socially excluded if (a) he or she is geographically resident in a society and (b) he or she does not participate in the normal activities of citizens in that society" (Burchardt, Le Grand and Piachaud, 1999: 230). Within our consumer culture, consumption is viewed as a "normal" and expected activity. As Bauman (2005: 38) states “ $a$ 'normal life' is the life of consumers, preoccupied with making their choices among the panoply of publicly displayed opportunities for pleasurable sensations and lively experiences." This paper focuses on low-income consumers whose financial resources results in them being unable to obtain the goods and services needed for an "adequate" and "socially acceptable" standard of living (Darley and Johnson, 1985: 206); in other words, consumers experiencing relative poverty and relative deprivation (Townsend, 1987) in consumer culture.

The aim of this paper is twofold. First, social policy studies surrounding social exclusion in terms of separation from mainstream society have focused on employment, often neglecting theorizing about the specific forms of social exclusion that can be associated with consumerism (Williams and Windebank, 2002, Hohnen, 2007). Equally although marketing and consumer research studies have arguably dealt with issues of exclusion (Andreasen, 1995), they have not specifically adopted a social exclusion discourse. Hence, it is demonstrated that a social exclusion framework provides a useful perspective to investigate issues facing those consumers whose limited financial resources contribute to consumption constraints. Second, given that social exclusion is seen as a process that "places persons, groups, communities and territories in a position of inferiority in relation to centres of power; resources and prevailing values" (Estivell, 2003: 19), it might be assumed that social 
exclusion goes hand in hand with consumer disempowerment. However, similar to Downey and Catterall (2007) findings suggest that some excluded consumers can be empowered. This is due to their high levels of consumer creativity in stigma management strategies and rejection of the stigmatising regime.

\section{The consumer culture}

In order to fully understand the excluded consumer it is necessary to document what constitutes normal consumption activity within consumer culture. It has been suggested that the following four conditions are necessary for a consumer culture; a substantial portion of a population consume at a level substantially above subsistence; exchange dominates selfproduction of objects of consumption; consuming is accepted as an appropriate and desirable activity and people judge others and themselves in terms of their consuming lifestyles (Rassuli and Hollander, 1986). Additionally, Lury (1996) suggests that modern consumption is characterised by an increase in consumer choice, the expansion of shopping as a leisure pursuit, the pervasiveness of advertising in everyday life, changing attitudes towards consumer debt, the political organisation by and of consumers and the increased visibility of consumer illnesses.

In a consumer culture, the marketplace acts as a framework for action (Arnould and Thompson, 2005). Baudrillard (1998: 29) goes so far as to suggest that consumption has a homogenizing effect and is responsible for the "total organization of everyday life." Indeed Campbell (2004) argues that not only do we live in a consumer society, but rather, a consumer civilisation. In this regard, consumption is even deemed to be a sign of good citizenship in response to a crisis situation. For example, after World War II, consumption was viewed as a civic responsibility to improve the living standards of all Americans (Cohen, 
2004). Similarly after the terrorist attack on 11 September 2001, people were encouraged to increase consumption (Hill, 2002).

Consumption exhibits a strong ideological hold on consumers. Indeed, the desire to participate in consumer culture is not promoted by material need; rather it is promoted by the belief that to find happiness one must be richer (Hamilton, 2004). Interaction with the marketplace provides consumers with resources for the construction of identity and emphasis is often placed on the portrayal of a socially acceptable image. Since the introduction of conspicuous consumption (Veblen, 1899), it has been recognised that social identity centres on the visibility of consumer goods and possessions. As well as a process of signification and communication, consumption can equally be analysed as a process of classification and social differentiation as consumers use goods as signs of affiliation with either their own reference group or with a group of higher status to which they wish to belong (Baudrillard, 1998).

Positive discourse heralds the benefits of a consumer society suggesting that choice can be seen as "the consumer's friend" (Gabriel and Lang, 2006: 1) and that consumers feel empowered when they are able to enjoy the consumption process. However, there has also been some negative discourse surrounding the consumer culture. Marketing techniques are often critiqued for creating a strong social pressure to consume, leading to feelings of exclusion and shame for those consumers who cannot make their desires a reality (Bowring, 2000). Advertising is attacked for presenting idealized and unrealistic pictures of daily life that cultivate people's perceptions of social reality and lead to unrealistic beliefs about what other consumers have and do (Richins, 1995). Fullerton and Punj (1997) also suggest that as well as stimulating legitimate consumption behaviour, the consumer culture can stimulate consumer misbehaviour. Previous research suggests that the poor may be particularly prone to consumer misbehaviour as their financial resources may not be sufficient to satisfy desires. 
To illustrate, Ozanne, Hill and Wright (1998) report that impoverished juvenile delinquents turn to crimes such as stealing cars in order to affirm their membership and status within their social groups. Likewise, Goldman and Papson (1998) indicate that poor youths may resort to crime in order to obtain their Nike trainers.

\section{Consumer Exclusion}

In today's consumer culture, as the standard of living rises, the gap between a subsistence income and a social inclusion income will continue to widen (Bowring, 2000). While economic growth and consumer culture has raised the standard of living for many, there are also concerns that income gaps between the rich and the poor have widened and inequality is deepening. It has been acknowledged that those living on a low income face consumer disadvantage in the marketplace (Andreasen, 1975) encountering various exchange restrictions and negative consequences (Hill and Stephens, 1997). It may be argued that excluded consumers are materially and socially deprived (Dekkers, 2008) which ultimately provokes stigmatization. Below, these issues are discussed with reference to the three competing discourses of social exclusion outlined by Levitas (1998), illustrating how a social exclusion discourse can link micro and macro level discussions.

\subsection{Material deprivation}

As well as being unable to obtain the goods and services needed for a socially acceptable standard of living (Darley and Johnson, 1985), low-income consumers encounter various other marketplace restrictions. Limited product availability can be a problem (Hill and Stephens, 1997). Smaller assortments have been partly attributed to access difficulties in both the food retailing industry (Cummins and Macintyre, 1999) and financial services industry (Leyshon and Thrift, 1995). Equally, low-income consumers often have to suffice 
with lower quality goods and services, for example, they may have no choice but to purchase second hand goods, an option that is almost always viewed as second best (Williams and Windebank, 2001). Additionally, since the publication of The Poor Pay More (Caplovitz, 1967), it has generally been accepted that they suffer price discrimination in the marketplace. For example, evidence of spatial dimensions of social exclusion (Villette and Hardill, 2007) has confirmed that supermarket prices are often higher in poor neighbourhoods (Chung and Myers, 1999).

Levitas' (1998) redistributionist discourse (RED) of social exclusion becomes relevant in this respect as this perspective links social exclusion to a lack of material resources. RED contrasts exclusion with a version of citizenship which calls for the redistribution of power and wealth. This coincides with Townsend's (1997) argument for a redistributive strategy through tax and benefit strategy, the reduction of earnings differentials and financial recognition of unpaid work. From an economic perspective, the emphasis rests on the structural institutions and processes that contribute to material and other forms of inequalities.

\subsection{Social deprivation}

One of the most extensive ways of operationalizing social exclusion is found in the Poverty and Social Exclusion (PSE) Survey of Britain which was conducted in order to capture what standard of living was considered acceptable by society (Gordon et al. 2000). Deprivation was determined by identifying items that more than 50 per cent of the population defined as necessities, but were missing due to a shortage of financial resources. An important result of the PSE survey is that the public holds ideas about the necessities of life that are more wide-ranging, or multi-dimensional, than is ordinarily represented in expert or political assessments. "People of all ages and walks of life do not restrict their interpretation 
of 'necessities' to the basic material needs of a subsistence diet, shelter, clothing and fuel. There are social customs, obligations and activities that substantial majorities of the population also identify as among the top necessities of life" (Gordon et al. 2000: 16). For low-income consumers, such social activities are often beyond reach as a large percentage of their money is tied up with essentials such as food and rent (Alwitt and Donley, 1996). This leads to a simplification of life's experiences (Andreasen, 1975) and exclusion from the leisure lifestyle. Low-income consumers may experience more difficultly in forming supportive relationships outside the immediate household (Daly and Leonard, 2002) due to limited opportunities for socialising. As a result, they do not have the opportunity to take advantage of "what life has to offer" and are cut off from what passes as a "happy life" (Bauman, 2005: 38).

Given that low-income consumers are often unemployed (Alwitt and Donley, 1996; O’Boyle, 1998), Levitas' (1998) social integrationist discourse (SID) of social exclusion becomes relevant. This perspective regards inclusion in terms of labour market attachment where employment is the main integrating force, thus reducing the cost of welfare provision. From this perspective, employment provides a socially accepted position within society thereby reducing social deprivation

\subsection{Stigmatisation}

From a social psychology perspective, stigma is a social construction that involves two components, first, the recognition of difference based on some distinguishing characteristic and secondly, the consequent devaluation of the person (Dovidio, Major and Crocker, 2000). As a result of their inability to match the rising consumption norms that are required for a socially acceptable standard of living, poor consumers have been described as "inadequate," "unwanted," "abnormal," "blemished, defective, faulty and deficient," "flawed 
consumers" and "non-consumers" (Bauman, 2005: 38, 112-113). Social barriers include reactions, attitudes and language as well as various other factors that label the poor as different and marginalize them from mainstream society. (Becker, 1997). The British Social Attitudes Report (National Centre for Social Research, 2008) highlights that a rising number of people place the blame for poverty on the poor themselves; some $27 \%$ think that poverty is due to "laziness or lack of willpower," up from 19\% in 1984. Many devalue the poor in this way, implying that personal failings make them different from the rest of society. This style of prejudice and discrimination threatens social identity and is a source of stress for stigmatized people (Miller and Kaiser, 2001).

The moral underclass discourse (MUD) of social exclusion (Levitas, 1998) deals with cultural explanations of poverty, concentrating on the moral and behavioural delinquency of the excluded themselves. This approach dictates that the poor are to blame for their own poverty as they have deviated from cultural and social "norms." For example, De Venanzi (2008) suggests that revulsion against the homeless population is largely driven by moral prejudices. This is often a gendered discourse that focuses on the delinquency of young men in terms of criminal behaviours and the delinquency of young women in terms of the irresponsibility of lone parenthood (Levitas, 1998). To date, experiences of stigmatisation have not featured highly on the policy agenda. Redistributionist and social integrationist discourses of social exclusion tend to dominate with little attention given to the moral underclass discourse.

\section{Methodology}

There is a need for identification and calculation of poverty and exclusion thresholds to be supplemented by the voice of the excluded themselves (Estivell, 2003). Consequently, this paper is based on qualitative analysis of 30 in-depth interviews with low-income families 
who encounter consumption constraints in the marketplace. In line with the feminization of poverty (Hill and Stephens, 1997), the study involved 25 lone parent families (24 lone mothers) and five two-parent families. Purposeful sampling was used for this project, which involved the selection of information-rich cases. Families were selected from urban areas of Northern Ireland; the majority of respondents were unemployed although a small number were working in low-paid jobs. The income level of the families averaged at $£ 150$ per week which is well below the results of the PSE Survey of Britain which indicated that the income after tax needed each week to escape overall poverty is $£ 239$ for all households (Gordon et al. 2000).

As poverty can affect the whole family unit, a family approach was adopted in that all households included at least one child under the age of 18 . In 16 families, a parent (normally the mother) was interviewed alone and in 14 families it was possible to arrange an interview with the main consumer decision maker along with their partner and/or children (aged 11 to 18). The interviewing of multiple family members permitted a deeper understanding of the family dynamics in terms of each person's role and influence in consumption decisions. Interview topics included everyday life (evaluation of circumstances relative to other families and friends, feelings about shortage of money and its effect on children), budgetary strategies (management of the household budget, acquisition sites for goods and services), hopes for the future, family background information and financial circumstances (sources of income, attitudes to credit). The respondents were encouraged to provide details about their daily lives and the emphasis was on obtaining the subjective perspectives of the respondents at the level of lived experience. A guide of interview topics was prepared but rather than being locked into one set of questions, a flexible approach allowed questions to be adapted to suit the direction of each interview. Interviews lasted approximately one hour and with respondents' permission were audio-recorded and later 
transcribed. Given the private and personal nature of the research, interviews were carried out in respondents' homes to ensure a familiar and comfortable environment. Pseudonyms are used to protect the identity of informants.

Hermeneutics was used to interpret the data. This is an iterative process, "in which a "part" of the qualitative data (or text) is interpreted and reinterpreted in relation to the developing sense of the "whole”" (Thompson, Pollio and Locander, 1994: 433). These iterations allow a holistic understanding to develop over time, as initial understandings are modified as new information emerges. First, each individual interview was interpreted. Secondly, separate interviews were related to each other and common patterns identified. In this paper we advance the data interpretation by using consumption stories to investigate macro constructs (Holt, 2002).

\section{Findings}

\subsection{Consumer Exclusion}

Findings reinforce the material and social deprivation experienced by low-income families with many respondents discussing the difficulty of meeting the families' needs and wants. Many find it challenging to heat their homes, cover electricity bills, provide good quality food and keep their homes in a good state of repair. The majority of respondents in this study are welfare dependent and consequently receive various conflicting messages from their structural environments. On the one hand, they are encouraged to adopt a frugal and necessity-driven approach to consumption in line with welfare benefits and on the other hand, marketing communications encourage participation in a never-ending cycle of hedonic consumption experiences. Consequently, thoughts of money are central to the lives of 
respondents and interview material clearly indicates that money is hegemonic in capitalist societies and it becomes a language that is impossible to avoid.

Denise: if you took families that are earning good wages and put them in here for a week and handed them my money they couldn't live on it. You have to be very wary, you really do. You have to watch the heating and watch what times you turn it on at and things like that. I mean like the tumble dryer in there, you would only use it in really really bad weather. It is shocking like, there are some weeks when I would have to borrow to get me through to the next week. (43, two parent family, 2 children).

Consumption is largely predetermined and impulse spending is rarely an option. Respondents employ smart budgeting strategies such as making lists and shopping in discount stores in efforts to stretch financial resources. Any unexpected expenses present a problem. Special occasions are also particularly challenging in terms of financial control, for example one respondent discussed the repercussions of heavy expenditure at Christmas extending into the New Year: it was March when I started getting back on my feet again (36, lone parent, 2 children).

The shopping experience is therefore utilitarian with few opportunities to act on hedonic shopping motivations. For many families financial resources are fully allocated to food, heating, electricity and other items that are deemed essential for survival meaning there is little remaining for hobbies and leisure activities or holidays. As one participant suggested, “oh, I don't go out, I don't go out, I can't afford to go out over the door, so I can't" (46, lone parent, 6 children). Another discussed the lack of spontaneity in terms of accessing entertainment opportunities: "if I wanted to go out with my friends I would have to start saving about 2 months before just so that I have enough money to go out"' (23, lone parent, 1 child). 
For many respondents, exclusion from consumption norms and the leisure lifestyle goes hand in hand with exclusion from the labour market. This can result in limited opportunities for social interaction, a monotonous existence and feelings of isolation. One respondent described this as follows:

“At the minute I'm very lonely... and when you get to my age you're nearly put on the shelf, you can't get jobs or nothing...there's nothing really for you. At the minute I'm just existing, I get her to school in the morning and I do my housework and I sit here" (45, lone mother, 3 children).

Other concurred indicating that they felt "stuck on the outside," and socially excluded. Findings reinforce the ways excluded consumers encounter stigmatization due to limited financial resources and reliance on welfare benefits. Thus, as well as dealing with the harsh realities of material and social deprivation such consumers also have to cope with the projection of negativity from other members of society.

Janice: "I know people do judge you, there are people who look down on you for what you wear and the way you talk, there are people who will look down on you for any reason" (23, lone parent, 2 children).

Julie: "there is a lot of emphasis on money but that's because of the way we are all brought up. Society is just geared to getting that job... you are expected to have the house and the car so you are pretty much judged. Single parents are judged a lot and it really annoys me" (24, lone parent, 1 child).

The projection of such negativity impacts on low-income consumers' self-image and consequently self-definition is influenced by perceived social definition (Baumen, 1998). This echoes Goffman's (1963: 18) suggestion that shame can be a central possibility arising 
from the individual's perception of falling short of "what he really ought to be." Feelings of inferiority can impact on the ways that people perceive their own ability for agency and many respondents experience feelings of powerlessness, something that has a detrimental impact on self-esteem. However, for some, the judgment from others encourages effort into fighting against the negative stereotypical image of poverty. Attempts to disguise or mask poverty are common through the portrayal of an image that minimizes visible signs of social difference.

\subsection{Stigma Management and consumer creativity}

While disempowerment may limit the agency of some respondents, this is not true for all. Indeed, many appear to condition themselves by learning to adapt their spending in line with financial incomings. Findings reveal that low-income consumers employ a variety of coping strategies to help them deal with and reduce the negative consequences that arise from their disadvantaged position in the marketplace. These include engaging in price comparisons, turning to the alternative sector (both the second-hand market and alternative financial sector), and searching for bargains.

Results demonstrate that a popular coping strategy employed by low-income consumers, involves using products and brands in unexpected and creative ways in an effort to reduce expenditure. To illustrate,

"The kids drink a lot of lemonade so I buy the 12p bottles from (discount store) and then buy all the different cordials so they can have any flavour of lemonade they want and I don't have to spend the money on Coke and Fanta and all the different brand names" (38, single parent, 2 children).

Brand simulation strategies such as the above were common, often in the context of concealing the use of generic branded products from children. This involves the disguise of the favoured 'top' brand with a more economically acceptable alternative, such as the generic. The generic brand is reworked and passed off as the genuine article; a common 
example involved refilling the packaging of an expensive brand of breakfast cereal with a low price generic. Through the integration of two brands with different images and value sets, low-income consumers avoid the perceived faults associated with each alternative.

Brand manipulation is also common as respondents substitute products with less expensive alternatives. At times this substitution can seem relatively logical (for example, one cleaning product for another), while on other occasions products are used in innovative and idiosyncratic ways (for example, Baby Wipes used as a cleaning product). In these cases, the objective is to look for cheaper options and find the most economical solution to meet needs. Low-income consumers thus employ various "tactics" (De Certeau, 1984) that undermine the ways in which marketers attempt to impose commodified meanings upon the consumer.

Some respondents are also creative in relation to prolonging the use-value of products, again with the aim of reducing expenditure. Examples of restoring furniture and updating clothing were common. The following comment provides a useful example of this: "I had a dress, a black dress, I got it a while ago in Miss Selfridge and I was looking for something to wear for my brother's party and I got the dress down and I tried it on and looked at it and I didn't like the way it went at the bottom but I really liked the top so I thought ahh, and I cut it off and made a top out of it and it was lovely, you would never had known the difference. Things like that I would change to suit, I would think is there something I could do with it? There was another top that had fringing on the arm and then when I washed it, it all went off so I cut it off and it's actually far nicer without it now" (25, lone mother, 1 child).

Extending the use value of furniture and clothing means that purchasing second hand clothing is less likely to be a necessity. Similar to Williams and Windebank (2002), the majority of respondents prefer to buy clothing new, normally in low cost clothing stores. A 
common reason given for the avoidance of second hand clothing shops was the potential embarrassment that would be felt if other people saw then entering second hand shops as this would convey to others that they were unable to afford new products. However, some respondents did make use of second hand clothing, primarily when they wanted to access brand name clothing that they would be unable to afford to purchase new.

"I would buy maybe one brand name thing a year at cost price in the charity shop......I'm lucky, there's a place....that would do second hand Diesel, instead of paying out for them, and they can range from $£ 50$ up to $£ 110$ for a 4 year old's pair of jeans, you can get them up the road for $£ 5$. The second hand shops in that area are very good because you're getting the second hand stuff from the wealthy people that live there" (23, lone mother, 2 children). As this comment demonstrates, the choice of second hand shop is critical in respondents' decision to purchase second hand clothing. Another respondent regularly visits a second hand shop that receives seconds (goods with a defect that prevents them being sold at full price) from a well-known high street chain. In this way, she can access the latest fashion at a fraction of the price. Thus, while Williams and Windebank (2002) suggest that second hand shopping is a negative experience for the poor, this study demonstrates that it can be an active, carefully considered choice. Indeed, some respondents were proud of their ability to obtain brand name and fashion clothing at good prices and were keen to provide examples of how their knowledge of their local areas enables them to make good decisions in terms of store choice.

\subsection{Rejecting the Stigmatising regime}

In this section, it is demonstrated that a normative definition of poverty can be problematic because not everyone desires to conform to mainstream society (Bowring, 2000). Rather, it may be possible to meet one's needs in unconventional ways or reformulate needs that differ from social expectations. Some respondents in the study were able to disengage 
themselves from the world of rising consumer aspirations, to illustrate, Nina discusses her resistance to using designer brand names as a basis for purchase decisions in relation to clothing for her 4 year-old daughter.

"Her clothes are nice and I don't really care where they come from. I wouldn't buy something just because it has a designer name on it" (24, lone mother, one child).

Nina constructs her own guidelines for appropriate consumption behaviour and does not feel compelled to follow the quest for increased possessions that is indicative of the consumer culture. Rather, she believes that people place too much emphasis on the acquisition of money and material possessions: "I think people are too materialistic about their occupations and their homes." Nina adopts a critical stance of the consumer society and implies that she is more interested in opportunities rather than the ownership of material possessions. This is reflected in her career plans. Nina is currently a full-time university student and is willing to sacrifice financial resources and material possessions in the short term with the hope that in the long term more opportunities will be available for her. As such, it could be suggested that Nina is prioritising cultural capital and using it to compensate for lack of economic capital (Bourdieu, 1986).

Equally not all respondents shared the view that normality is equated with the ability to consume. For example, Lorraine implied that it is "normal" to live a value and budget conscious lifestyle and it is those who overspend who are acting irrationally.

"I was in a mothers and toddlers group with the one I do the babysitting for, they're all in exactly the same position and they were talking about a shop which I never heard of, it's a kid’s shop and it was $£ 75$ for a jumper for a 2 year-old. I said 'sure it'll only fit them 3 or 4 months, ' I could see through it if you or I got it, I bet you would never pay $£ 75$ for a jumper!" (43, lone mother, three children). 
Consumers who spend money on expensive clothing are perceived by Lorraine as being excessive and she exhibits disbelief of a more affluent lifestyle. This is similar to Goffman's (1963: 22) suggestion that individuals may reject the stigmatised label by acknowledging "the limitations of normals." This may be viewed as a coping strategy as by critiquing the behaviour of overspent consumers, Lorraine rationalises her own consumption behaviour. She is proud of her consumer skills of sourcing good value products from markets, discount shops and sales and is keen to provide examples of the advantages that this brings.

The normal customs of a society may be dictated by two sets of influences; larger societal influences and those coming from the consumer's own narrow society, in other words, their own neighbourhoods and peer groups which may consist of other excluded consumers. The realisation that others are in similar positions reduces consumers' feelings of relative deprivation, lowering the comparability standard and instilling feelings of successful coping.

Rebecca: “We manage ok, we're not like some people who are really struggling you know what I mean, I'd like to think I've done ok out of the money that I have to live on" (23, two parent family, 2 children).

It is comforting for these consumers to know that there are others who are in worse positions than they are. Others shared this view with comments such as "there's somebody somewhere worse than me so I'm not too bad that way" and "compared to some people and compared to what's going on in the world I've got a lot to be thankful for." Social psychology literature suggests that downward social comparison can involve stigmatising others who are less fortunate in order to increase one's own sense of subjective well-being and boost self-esteem (Dovidio, Major and Crocker, 2000). 


\section{Discussion}

Making exclusion visible and giving it recognition represents the first stage in the formulation of strategies to combat it (Estivell, 2003). To provide a deeper understanding of the experiences of excluded consumers, evidence is presented to highlight the ways in which separation from the mainstream consumption norms of consumer culture through material and social deprivation can result in stigmatisation. For some, this leads to negative emotions and disempowerment and for others, it incites the employment of stigma management strategies through creative consumer coping. Paradoxically, then, whilst on the one hand the inability to partake fully in consumer society can result in marginalisation, it also provides the resources to avoid this stigmatisation if people can cope creatively (for a further example of this see Gowan's (1997) research on homeless scavengers).

Given the multidimensional nature of consumer well-being (Lee et al. 2002), the broad perspective offered by social exclusion represents a move away from the concept of well-being as primarily financial. Instead of focusing only on people's ability to afford consumption opportunities, a social exclusion perspective allows consideration of wider policy issues such as goods acquisition practices (Williams and Windebank, 2002) and social barriers to inclusion. As a consequence, it raises a number of policy issues in relation to ways of helping excluded consumers.

One of the key policy issues is to recognize the role of other members of society in enhancing the problems of poor consumers. It appears that policy in this area has been neglected in favour of social integrationist and redistributionist policy. However, this study demonstrates that social stigma has a large influence on the actions and self-perceptions of poor consumers. Consumer education programmes aimed at overcoming social barriers could be implemented. There may also be scope to include elements of this in the school curriculum. For example, Media Smart (www.mediasmart.org.uk) offers media literacy 
educational resources for children with the aim of encouraging 6 to 11 year olds to think critically about the role of advertising in their everyday lives. If children understand better how society works, they may be better able to resist its pressures. Given that many of the children included in the research appeared to be so brand conscious, resources such as Media Smart, that promote a greater understanding of peer pressure vis-à-vis brand culture are important. Future consumer education programmes should also highlight the need to avoid stereotypes that conflate all poor consumers as a social problem.

Additionally although the task of eradicating or preventing poverty is a political matter (Becker, 1997) and marketers cannot be responsible for increasing the resources and opportunities available to poor consumers, the role of marketers in contributing to consumer exclusion should be considered. Inevitably, marketing contributes to the consumer culture through the display of desire-inducing symbols (Arnould and Thompson, 2005) and techniques that increase awareness of social comparison. The exchange relationship between marketers and poor consumers is imbalanced in favour of the marketer. As such, continual monitoring of marketing activities is needed to ensure that unethical practices are not being implemented. For example, previous cases of such practices include supermarkets charging higher prices in poor neighbourhoods in the UK (Monbiot, 2000) and local shops increasing the price of goods to correspond with the issue of welfare support cheques in the US (Bell and Burlin, 1993). Initiatives that increase the power of poor consumers in exchanges would be welcome. These could include individualised payment plans that allow consumers control of their own budgeting strategies or credit opportunities that are specifically tailored to the needs of low-income consumers (see Fuller et al. 2006). Indeed, the findings demonstrate that when consumers do increase their power in exchange relationships such as through price comparisons or the bulk purchasing of discounted items, feelings of disempowerment are less evident. 
Policy also needs to recognize that poor consumers do not want to be considered as victims but rather, they want to take an active role in coping with consumption constraints. Knowledge of stigma management strategies could be implemented into programmes to enable self-empowerment for poor consumers. The findings suggest that low-income consumers may use a wide range of highly innovative budgeting strategies. Knowledge of these strategies could be more widely disseminated to other consumers which may be particularly helpful to people when they are first confronted with a drop in income (e.g. through job loss) as they could learn from the experiences of others. Increased recognition of the functional (for example, the search for bargains) and dysfunctional (for example, alcohol consumption) coping strategies employed by low-income consumers should also prove useful for organisations that represent consumer interests, as it would help them to better serve their members and aid with the development of consumer education programs.

For many consumers, the consumption standards of the consumer culture represent an ideal and serve as an important comparison point. However, it is important to recognize that some consumers voluntarily exclude themselves from the marketplace. As Bowring's (2000: 313) discussion of the "tyranny of normality" highlights, there are limitations to considering deprivation solely in terms of normative exclusion because the happiness and self-esteem of everyone cannot possibly be achieved by conforming to the mainstream society. Normality is a construct and some respondents redefined normality to suit themselves and to reflect their own lives, i.e. what is normal for them. This redefining of normality can be viewed in relation to control. It has been acknowledged that poor consumers often experience feelings of powerlessness, and that their lives are controlled by external events (Alwitt and Donley, 1996). Henry (2005) suggests that perceptions of relative power effect self-worth evaluations. Consequently feelings of lack of control may inhibit consumer empowerment. In the study reported here, the redefinition of normality can be interpreted as a way of 
regaining control over one's life. A similar situation has been found in other groups of consumers who have limited engagement with the marketplace, such as voluntary simplifiers who seek to regain control over their lives and avoid perceived shortcomings of the consumer society (Bekin, Carrigan and Szmigin, 2005).

By highlighting the consumption behaviour of low-income consumers and illustrating that is possible to be happy without participating in all the consumer society has to offer, we can become more aware of those consumers who are high spenders. The issue of excess consumption becomes more apparent in light of these revelations concerning the lives of lowincome consumers. Baudrillard (1998) highlights the positive side of waste, suggesting that it is the consumption of surplus that allows the consumer to feel that he/she is alive. However it is clear that this idea needs to be treated with caution. The bestseller, Affluenza by De Graaf et al. $(2005,2)$ illuminated the problems associated with an excessive quest for material gain. They defined affluenza as "a painful, contagious, socially transmitted condition of overload, debt, anxiety and waste resulting from the dogged pursuit of more" and highlight the individual and societal problems that arise from possession overload.

The images of bingeing, excess and overload depicted by research on excess consumption highlights the possibility of a dysfunctional relationship with money and consumption. Increasingly social problems stem from affluence, not poverty, for example, Schlosser's (2001) Fast Food Nation and Morgan Spurlock's documentary, Supersize Me both demonstrate how over-eating has created an obesity epidemic. Excess consumption can also be associated with crime. To illustrate, Hirschman (1992) found that drug users were prone to illegal activities in terms of both purchasing and using illegal drugs and engaging in crime to obtain money to purchase the drugs. All of this suggests that we live in a culture that thrives on excess, highlighting the dark side of consumption. The irony of this is evident when we consider research indicating a low correlation between income and subjective well 
being (Ahuvia and Friedman, 1998). In fact, it has been suggested that excessive concern for material goods is actually a sign of dissatisfaction with life and higher-order needs, (as opposed to basic needs), such as the need for self-actualisation, cannot be met through consumption (Zavestoski, 2002). This raises the desire versus need debate, again an issue that becomes more salient for those who have to struggle to obtain a relationship with goods. 


\section{References}

Ahuvia, A.C. and Friedman, D. C. (1998), "Income, Consumption and Subjective Well-being: Toward a Composite Macromarketing Model", Journal of Macromarketing, Vol. 18, No.2, pp. 153-168.

Alwitt, L. F. and Donley, T. D. (1996), The Low-Income Consumer, Adjusting the Balance of Exchange, Sage, Thousand Oaks, CA.

Andreasen, A.R. (1975), The Disadvantaged Consumer, The Free Press, New York.

Arnould, E. J. and Thompson, C. J. (2005), “Consumer Culture Theory (CCT):

Twenty Years of Research”, Journal of Consumer Research, Vol. 31, No. 4, pp. 868-82.

Baudrillard, J. (1998), The Consumer Society, Sage, London.

Bauman, Z. (2005), Work, Consumerism and the New Poor, Open University Press, Buckingham, $2^{\text {nd }}$ edition.

Becker, S. (1997), Responding to Poverty: The Politics of Cash and Care, Longman, London.

Bekin, C., Carrigan, M. and Szmigin, I. (2005), “Defying marketing sovereignty: voluntary simplicity at New Consumption Communitiesw, Journal of Qualitative Market Research, Vol. 8, No. 4, pp. 413-429,

Bell, J. and Burlin, B. M. (1993), "In Urban Areas: Many of the Poor Still Pay More for Food", Journal of Public Policy and Marketing, Vol. 12, No. 2, pp. 268-71.

Bourdieu, P. (1986), “The Forms of Capital,” in Richardson, J.G (Ed.), Handbook of Theory and Research for the Sociology of Education, Greenwood Press, New York, pp. 241258. 
Bowring, F. (2000), "Social Exclusion: Limitations of the Debate," Critical Social Policy, Vol. 20, No. 3, pp. 307-30.

Burchardt, T., Le Grand, J., and Piachaud, D. (1999), "Social Exclusion in Britain 1991-1995", Social Policy and Administration, Vol. 33, No. 3, pp. 227-44.

Campbell, C. (2004), "I Shop Therefore I Know that I am: The Metaphysical Basis of Modern Consumerism”, in Ekström, K. and Brembeck, H. (Eds.) Elusive Consumption, Berg, Oxford, pp. 27-44.

Caplovitz, D. (1967), The Poor Pay More, Consumer Practices of Low-Income Families, The Free Press, New York.

Chung, C. and Myers, S.L. (1999), "Do the Poor Pay More for Food? An Analysis of Grocery Store Availability and Food Price Disparities", The Journal of Consumer Affairs, Vol. 33, No. 2, pp. 276-296.

Cohen, L. (2004), “A Consumers’ Republic: The Politics of Mass Consumption in Postwar America", Journal of Consumer Research, Vol. 31, No. 1, pp. 236-239.

Daly, M. and Leonard, M. (2002), Against All Odds: Family Life on a Low Income in Ireland, Combat Poverty Agency, Dublin: Ireland.

Cummins, S. and Macintyre, S. (1999), “The Location of Food Stores in Urban Areas: A Case Study in Glasgow", British Food Journal, Vol. 101, No. 7, pp. 545-553.

Darley, W.K. and Johnson, D. M. (1985), “A Contemporary Analysis of the Low Income Consumer: An International Perspective", in Tan, C.T and Sheth, J.N (Eds.) Historical Perspectives in Consumer Research: National and International Perspectives, Association for Consumer Research, Provo: UT, pp. 206-210. 
De Certeau, M. (1984), The Practice of Everyday Life, University of California Press, London.

De Graaf, J., Wann, D. and Naylor, T. (2005), Affluenza: The All-Consuming Epidemic, Berrett-Koehler, San Francisco:CA, $2^{\text {nd }}$ edition.

De Venanzi, A. (2008), “The institutional dynamics of homelessness; The United States of America and Japan compared", The International Journal of Sociology and Social Policy, Vol. 28, No. 3/4, pp. 129-145.

Dekkers, G. J. M. (2008), “Are you Unhappy? Then you are poor! Multi-dimensional Poverty in Belgium", The International Journal of Sociology and Social Policy, Vol. 28, No. 11/12, pp. 502-515.

Dovidio, J. F., Major, B. and Crocker, J. (2000), “Stigma: Introduction and Overview”, in Heatherton, T.F., Kleck, R.E., Hebl, M.R. and Hull, J. G. (Eds.), The Social Psychology of Stigma, The Guilford Press, New York.

Downey, H. and Catterall, M. (2007), “Autopoiesis and the Home-confined Consumer; The role of Personal Communities", The International Journal of Sociology and Social Policy, Vol. 27, No. 3/4, pp. 175-188.

Estivill, J. (2003), Concepts and Strategies for Combating Social Exclusion: An Overview, International Labour Office, Portugal.

Fuller, D., Mellor, M. and Dodds, L. (2006), "Consulting the Community: Advancing Financial Inclusion in Newcastle upon Tyne, UK", The International Journal of Sociology and Social Policy, Vol. 26, No. 5/6, pp. 255-271.

Fullerton, R.A. and Punj, G. (1997), “The Unintended Consequences of the Culture of Consumption: An Historical-Theoretical Analysis of Consumer Misbehavior", Consumption, Markets and Culture, Vol. 1, No. 4, pp. 393-423. 
Gabriel, Y. and Lang, T. (2006) The Unmanageable Consumer: Contemporary Consumption and its Fragmentation, Sage, London, 2nd edition.

Goffman, E. (1963), Stigma: Notes on the Management of Spoiled Identity, Penguin Books, London.

Goldman, R. and Papson, S. (1998), Nike Culture: The Sign of the Swoosh, Sage, London.

Gordon, D., Adelman, L., Ashworth, K., Bradshaw, J., Levitas, R., Middleton, S., Pantazis, C., Patsios, D., Payne, S., Townsend, P. and Williams, J. (2000), Poverty and Social Exclusion in Britain, Joseph Rowntree Foundation, York.

Gowan, T. (1997), “American Untouchables: Homeless Scavengers in San Francisco's Underground Economy", The International Journal of Sociology and Social Policy, Vol. 17, No. 3/4, pp. 159-190.

Hamilton, C. (2004), Growth Fetish, Pluto Press, London.

Henry, P. C. (2005), “Social Class, Market Situation, and Consumers’ Metaphors of (Dis)Empowerment”, Journal of Consumer Research, Vol. 31, No. 4, pp. 766-778.

Hill, R. P. (2002), "Consumer Culture and the Culture of Poverty: Implications for Marketing Theory and Practice”, Marketing Theory, Vol. 2, No. 3, pp. 273-93.

Hill, R.P. and Stephens, D.L. (1997), "Impoverished Consumers and Consumer Behavior: The Case of AFDC Mothers", Journal of Macromarketing, Vol. 17, No. 2, pp. 3248.

Hirschman, E (1992), "The consciousness of addiction: toward a general theory of compulsive consumption", Journal of Consumer Research, Vol. 19, No.2, pp.155-79.

Hohnen, P. (2007), "Having the Wrong Kind of Money. A Qualitative Analysis of new Forms of Financial, Social and Moral Exclusion in Consumerist Scandinavia", The Sociological Review, Vol. 55, No.4, pp. 748-767. 
Lee, D.J., Sirgy, J.M., Larsen, V. and Wright, N.D. (2002), “Developing a Subjective Measure of Consumer Well-Being”, Journal of Macromarketing, Vol. 22, No. 2, pp. 158169.

Levitas, R. (1998), The Inclusive Society? Social Exclusion and New Labour, Macmillan, Basingstoke.

Leyshon, A. and Thrift, N. (1995), “Geographies of Financial Exclusion: Financial Abandonment in Britain and the United States", Transactions - Institute of British Geographers, Vol. 20, pp. 312-341.

Lury, C. (1996), Consumer Culture, Polity Press, Oxfordshire.

Miller, C. and Kaiser, C. (2001), "A Theoretical Perspective on Coping with Stigma", Journal of Social Issues, Vol. 57, No. 1, pp. 73-112.

Monbiot, G. (2000), Captive State: The Corporate Takeover of Britain, Pan Books, London.

National Centre for Social Research (2008), British Social Attitudes, The $24^{\text {th }}$ Report, Sage, London.

O’Boyle, E. J. (1998), “Transitions Into and Out of Poverty”, International Journal of Social Economics, Vol. 25, No. 9, pp. 1411-1424.

Ozanne, J. L., Hill, R. P. and Wright, N. D. (1998), “Juvenile Delinquents’ Use of Consumption as Cultural Resistance: Implications for Juvenile Reform Programs and Public Policy”, Journal of Public Policy and Marketing, Vol. 17, No. 2, pp. 185-196.

Rassuli, K. M. and Hollander, S. C. (1986), “Desire - Induced, Innate, Insatiable?”, Journal of Macromarketing, Vol. 6 (Fall), pp. 4-24.

Richins, M. L. (1995), “Social Comparison, Advertising and Consumer Discontent”, American Behavioral Scientist, Vol. 38, No. 4, pp. 593-607. 
Schlosser, E. (2001), Fast Food Nation: The Dark Side of the All-American Meal, Allen Lane, London.

Townsend, P. (1987), “Deprivation”, Journal of Social Policy, Vol. 16, No. 2, pp. 125-146.

Townsend, P. (1997), "Redistribution: The Strategic Alternative to Privatisation", in Walker, A. and Walker, C. (Eds.), Britain Divided: The Growth of Social Exclusion in the 1980s and 1990s, CPAG, London, pp. 263-278.

Thompson, C. J., Pollio, H. R. and Locander, W. B. (1994), “The Spoken and the Unspoken: A Hermeneutic Approach to Understanding the Cultural Viewpoints that Underlie Consumers' Expressed Meanings", Journal of Consumer Research, Vol. 21, No. 3, pp. 43252.

Veblen, T. (1899), Conspicuous Consumption, Penguin Books, London.

Williams C. C. and Windebank, J. (2002), “The "Excluded Consumer”: A Neglected Aspect of Social Exclusion?” Policy \& Politics, Vol. 30, No. 4, pp. 501-13.

Villette, S. M. and Hardill, I. (2007), "Spatial peripheries, Social Peripheries: Reflections on the "suburbs" of Paris", The International Journal of Sociology and Social Policy, vol. 27, No. 1/2, pp. 52-64.

Zavestoski, S. (2002), “The Social-Psychological Bases of Anticonsumption Attitudes", Psychology and Marketing, Vol. 19, No. 2, pp 149-165. 